\title{
Synthesis, characterization and biological evaluation of novel tetrasubsituted Imidazole compounds
}

\author{
Khurram Shahzad ${ }^{1}$, Faheem Abbas*1 ${ }^{1}$, Digvijay Pandey ${ }^{2}$, Sanila Ajmal ${ }^{1}$, Mudassar Khadim ${ }^{3}$, Muhammad Usman
} Tahir $^{3}$

${ }^{1}$ Department of Chemistry, University of Agriculture Faisalabad-38000, Pakistan. ${ }^{2}$ Department of Technical Education, IET, Lucknow-226021, India. ${ }^{3}$ Department of chemistry, Government College University Faisalabad-38000, Pakistan.

\begin{abstract}
New classes of tetrasubsituted imidazole based compounds were synthesized using multicomponent one pot synthesis scheme through cyclocondensation reaction of benzil, aromatic primary amines, aldehydes and ammonium acetate in glacial acetic acid. The synthesized compounds have been analyzed and characterized by melting point, color, conductivity method, CHN analysis, FT-IR and UVVisible. The reaction proceeding was examined by TLC after regular intervals of period. To test biological activity, the synthesized compounds have been examined against various bacterial strains. From the analysis of the antibacterial activity of these synthesized compounds demonstrated that all three imidazole compounds have considerable to significant activity against the strains, and compound K2 was found potent comparatively.
\end{abstract}

Keywords: Tetrasubsituted imidazoles, synthesis, cyclocondensation reaction, characterization, antibacterial activity, compound K2.

Citation: Khurram Shahzad et.al. (2020) Synthesis, characterization and biological evaluation of novel tetrasubsituted Imidazole compounds . Journal of PeerScientist 3(1): e1000019.

Received April 20, 2020; Accepted June 04, 2020; Published June 18, 2020.

Copyright: (C) 2020 Khurram Shahzad et.al. This is an open-access article distributed under the terms of the Creative Commons Attribution License, which permits unrestricted use, distribution, and reproduction in any medium, provided the original author and source are credited.

Funding: This research received no specific grant from any funding agency in the public, commercial, or not-for-profit sectors.

Competing Interests: The authors have declared that no competing interests exist.

* E-mail: faheemabbas78688@ gmail.com | Phone: +92-3057806672

\section{INTRODUCTION}

I midazole was discovered in $1840 \mathrm{~s}$ and after its discovery a flood of research and development on imidazole based compounds is carrying out due to its large number of applications such as pharmaceutical drugs, agrochemicals, ligands, and synthetic acceptors, catalysts and so on. [1-4]. Imidazole based compounds have special place in the field of medicinal drugs [5]. For the treatment of various ailments, a variety of imidazole derivatives 1) 1H-imiidazole, 2) (z)-N-(cyclohexa-2,4dienyl)-N-methylformamidine, 3) 4,5-dihydro- $1 \mathrm{H}$ imidazole, 4) 2,5-dihydro-1H-imidazole, 5) 2,3-dihydro1H-imidazole and 6) Imidazolidine (figure 1) are playing vital role and researchers are exploiting novel imidazole derivatives with medicinal applications [6-7]. Imidazole ring has special structural features which enable it to interact with many enzymes and receptors in biotic entities through ion-dipole, hydrogen bonds, $\pi-\pi$ stacking, coordination, cation $-\pi$, van der Waals forces and so on [8-10].

The various biological activities of imidazole derivatives are attributed to presence of imidazole ring in many vital biological molecules such as deoxyribonucleic acid (DNA), histamine, vitamin B12 and hemoglobin [1113]. It is widely used to design and

synthesize

biologically active molecules as it is<smiles>c1ccc2[nH]cnc2c1</smiles>

(1)<smiles>C1=NCNC1</smiles>

(3)
(4)<smiles>C1=CNCC1</smiles>

(5)
(6) considered as iso-stere of triazole ,oxazole, pyra-zole, thiazole, tetrazole, amides and so on [14-16]. The review of literature unveiled that imidazole based compounds have potential applications such as anticancer, antihypertensive, anti-histaminic, anti-neurophatic, antihemolytic, cytotoxic, antimycobacterial, antioxidant, and antimicrobial and so on [17-20].

A large number of imidazole based compounds with medicinal applications have been reported like 


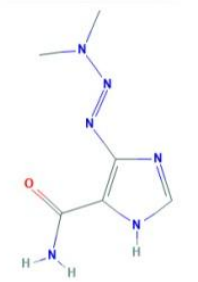

Dacarbazine C6H10N6O CAS number - 4342-03-4 III

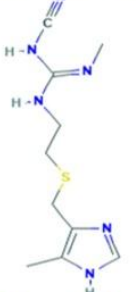

Cimetidine C10H16N6S CAS number - 51481-61-9

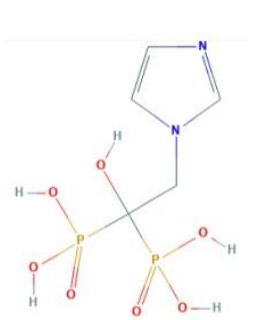

Zoledronic acid C5H10N2O7P2 CAS number - 118072-93-8

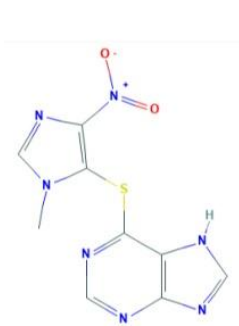

Azathioprine C9H7N7O2S C9H7N702S
CAS number - 446-86-6

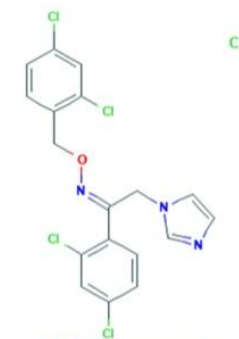

Oxiconazole C18H13C14N3O

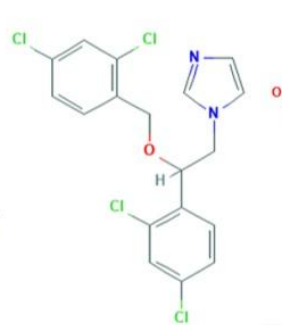

Miconazole C18H14Cl4N2O

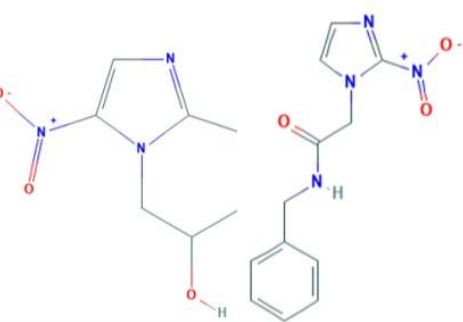

Secnidazole Benznidazole C7H11N3O3 $\mathrm{C} 12 \mathrm{H} 12 \mathrm{~N} 4 \mathrm{O} 3$ CAS number 22994-85-0

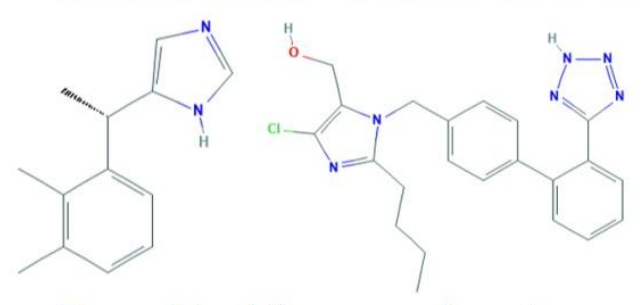
Dexmedetomidine

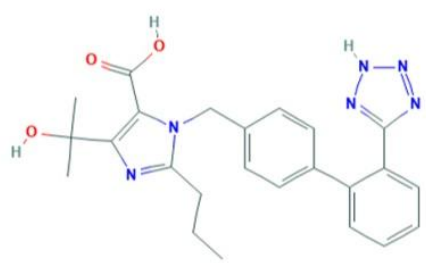

Olmesartan

$$
\mathrm{C} 24 \mathrm{H} 26 \mathrm{~N} 6 \mathrm{O} 3
$$

CAS number - 144689-24-7

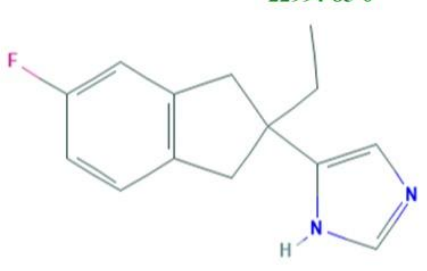

Fipamezole C14H15FN2

CAS number - 150586-58-6

Figure 2: 2D representations of dacarbazine, zoledronic acid, azathioprine, oxiconazole, miconazole, secnidazole, benznidazole, cimetidine, dexmedetomidine, losartan, olmesartan and fipamezole compounds.

dacarbazine, zoledronic acid and azathioprine as anticancer, oxiconazole and miconazole as antifungal, secnidazole and benznidazole as antiparasitic, cimetidine and dexmedetomidine as antihistaminic, losartan and Olmesartan as anti-hypertensive, dexmedetomidine and fipamezole as antineuropathic (figure 2) [10, 21-23]. To treat infections, the introduction of antibacterial drugs has been acknowledged as one of the preeminent success of the century.

Some reported imidazole based antibacterial drugs such as Metronidazole (1a), ornidazole (1b), secnidazole (1c), and tinidazole (1d) are shown in figure $3[10,24-$ 25]. There are different approaches for imidazole synthesis based compounds but among all routes, multicomponents one pot synthesis is convenient and widely used method in organic reactions and pharmaceutical chemistry [26]. This method is highly efficient, economical and gives high yield of desired products [27]. Multicomponent synthesis is also widely used method for the synthesis of imidazole based compounds especially for tetrasubsituted ones. Tetrasubsituted imidazole is a class of imidazole with high medicinal chemistry and biochemical process [28] and possess potential applications as analgesic, antiinflammatory [29], fungicidal, antibacterial and antitumor activities [30]. Therefore, synthesis of tetrasubsituted imidazole has become of remarkable importance for recent years globally. In current study, we report the synthesize of three tetrasubsituted imidazole compounds (K1, K2 and K3) via cyclocondensation of 1,2-diketone ( benzyl ), aldehydes, primary amines and ammonium

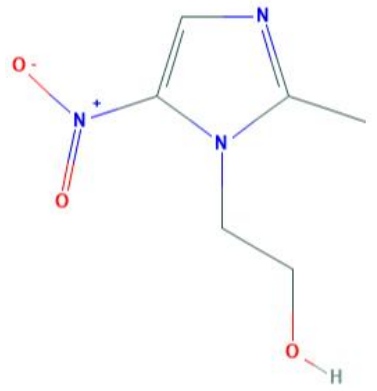

Metronidazole

$\mathrm{C} 6 \mathrm{H} 9 \mathrm{~N} 3 \mathrm{O} 3$

CAS number - 443-48-1

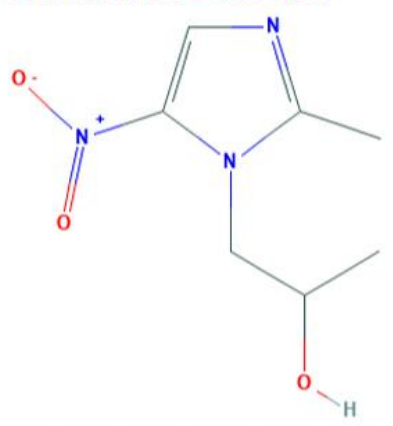

Secnidazole

$\mathrm{C} 7 \mathrm{H} 11 \mathrm{~N} 3 \mathrm{O} 3$

CAS number - 3366-95-8

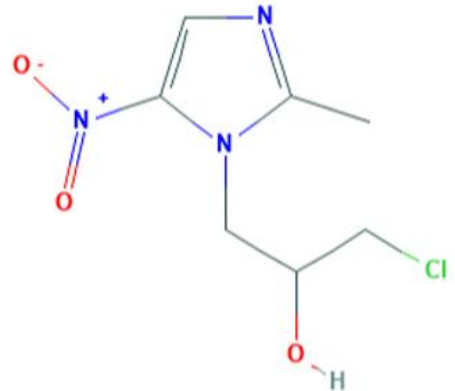

Ornidazole

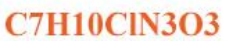

CAS number - 16773-42-5

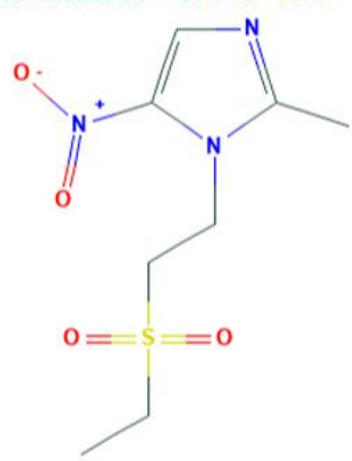

Tinidazole

C8H13N3O4S

CAS number - 19387-91-8
Figure 3: 2D representations of Metronidazole, Ornidazole, Secnidazole and tinidazole compounds.

acetate using glacial acetic acid as a catalyst. The newly synthesized compounds; 5-methyl-2-(2-methyl-4,5- 
diphenyl-1H-imidazol-1-yl)phenol (K1), 2-[2-(furan-2yl)-4,5-diphenyl-1H-imidazol-1-yl]-5- methylphenol (K2) and 5-methyl-2-(2, 4, 5-triphenyl-1H-imidazole-1-yl) phenol (K3) (figure 4) were initially analyzed by physical methods such as solubility, melting point, conductivity and thin layer chromatography (TLC) and then with spectroscopic techniques like UV-Visible and FT-IR. The synthesis and computer study of compounds entitled as $\mathrm{K} 1, \mathrm{~K} 2$ and $\mathrm{K} 3$ never reported previously according to our best of knowledge.

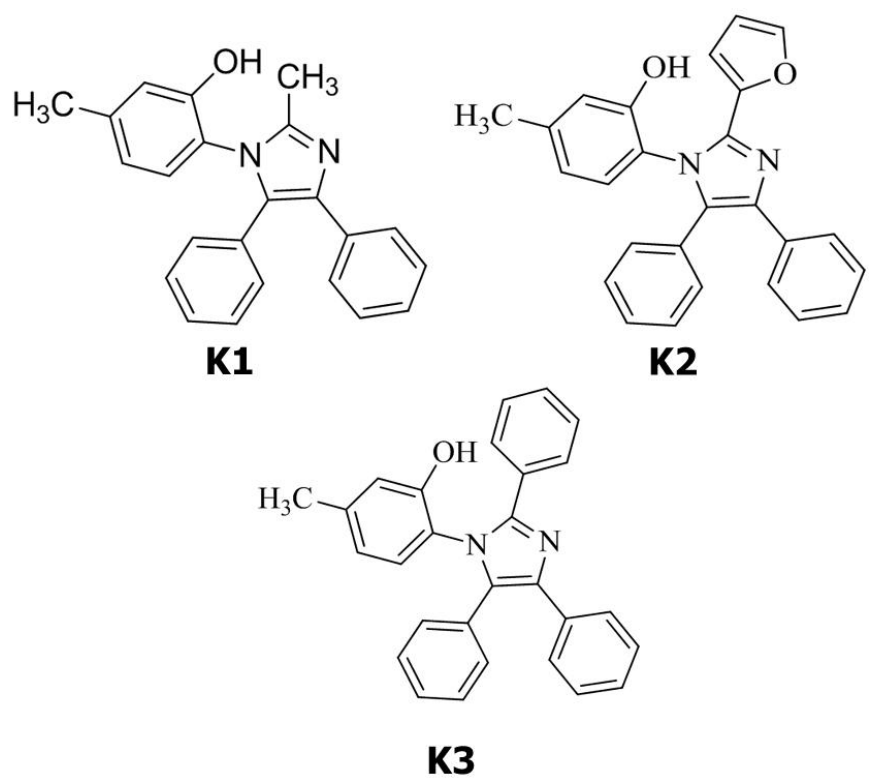

Figure 4: 2D representations of compounds K1,K2 and K3.

\section{RESULTS AND DISCUSSION Physical characteristics}

Color / Melting point / Physical appearance / yield:

The newly prepared tetrasubsituted imidazole derivatives (K1, K2 and $\mathrm{K} 3$ ) inert against climate and humidity at room temperature.. They exist in crystalline form and have color differentiates. Color, physical appearance and melting points of synthesized compounds are shown in table 1 .

Table 1: Melting point, color, physical appearance and yield of synthesized compounds (K1, K2 and K3):

\begin{tabular}{cccc}
\hline Parameter & K1 & $\begin{array}{c}\text { Compound } \\
\text { K2 }\end{array}$ & K3 \\
\hline Color & $\begin{array}{c}\text { Blackish } \\
\text { brown }\end{array}$ & Brown & Yellow \\
$\begin{array}{c}\text { Melting } \\
\text { point }\left({ }^{\circ} \mathbf{C}\right)\end{array}$ & $182-184$ & $195-197$ & $206-208$ \\
$\begin{array}{c}\text { Physical } \\
\text { appearance } \\
\text { \% of yield }\end{array}$ & Crystalline & Crystalline & Crystalline \\
\hline
\end{tabular}

\section{Conductance Values:}

The conductivity of synthesized compounds was determined at room temperature. About $1 \mathrm{M}$ solution of synthesized compounds was prepared using DMSO as a solvent to check their conductance. The conductance values of synthesized compounds were low as they are organic compounds of covalent nature and nonelectrolyte having conductivity range from 12 to $15 \Omega$ ${ }^{1} \mathrm{~cm}^{-2} \mathrm{~mol}^{-1}$ as shown in table 2 .

Table 2: Conductance values of synthesized compounds (K1, $\mathrm{K} 2$ and $\mathrm{K} 3$ ):

\begin{tabular}{cccc} 
& \multicolumn{3}{c}{ Compound } \\
Parameter & K1 & K2 & K3 \\
\hline$\Omega^{-1} \mathrm{~cm}^{-2} \mathrm{~mol}^{-1}$ & 15 & 13 & 12 \\
\hline \multicolumn{4}{c}{ U V-Visible study }
\end{tabular}

The $\lambda$ max of all synthesized compounds was determined experimentally in the solvent phase. The experimentally determined values are tabulated in table 3 . It was observed that compound $\mathrm{K} 3$ has highest $\lambda \max$ while $\mathrm{K} 1$ possess lowest one.

Table 3: גmax values of synthesized compounds (K1, K2 and $\mathrm{K} 3)$ :

\begin{tabular}{cccc} 
& \multicolumn{3}{c}{ Compound } \\
Parameter & K1 & K2 & K3 \\
\hline$\lambda \max (\mathrm{nm})$ & 265 & 316 & 361 \\
\hline
\end{tabular}

\section{IR Spectra of synthesized compounds (K1, K2 and K3}

Agilent technology (Cary-620) FTRIR spectrophotometer was used to obtain and interpret IR Spectra of newly synthesized tetrasubsituted imidazole derivatives (K1, $\mathrm{K} 2$ and $\mathrm{K} 3$ ).

\section{IR Spectra of 5-methyl-2-(2-methyl-4,5-diphenyl-1H- imidazol-1-yl)phenol (K1)}

Selected IR values of K1 are given in Table 4. The IR spectra of $\mathrm{K} 1$ exhibited that a new peak is revealed at $1650 \mathrm{~cm}^{-1}$ which may be due to presence of stretching frequency of $\mathrm{C}=\mathrm{N}$. This indicates that the probable imino bond $(\mathrm{C}=\mathrm{N})$ might be shaped due to cyclocondensation of benzil, primary amine, aldehyde and ammonium acetate. The $\mathrm{C}-\mathrm{N}$ peak occurred at 1440 cm-1, which also suggests the development of the required compound. Peak appeared at $3345 \mathrm{~cm}^{-1}$ due to $\mathrm{O}-\mathrm{H}$ stretching frequency. New peaks observed at $3050 \mathrm{~cm}^{-1}$ and $2912 \mathrm{~cm}^{-1}$ due to $\mathrm{sp}^{2}(\mathrm{C}-\mathrm{H})$ and $\mathrm{sp}^{3}(\mathrm{C}-$ $\mathrm{H})$ stretching frequencies. Peak at $1680 \mathrm{~cm}^{-1}$ was vanished that directs the absence of benzil. However, the remaining peaks of different groups did not undergo significant change. 


\section{IR spectra of 2-[2-(furan-2-yl)-4,5-diphenyl-1H- imidazol-1-yl]-5-methylphenol (k2)}

The few selected IR values of K2 are given in Table 4. Data revealed that the bands due to the azomethine $(-\mathrm{C}=\mathrm{N}-)$ linkage observe at $1658 \mathrm{~cm}^{-1}$. The peak of C-N occurred in the range of $1419 \mathrm{~cm}-1$. The peak due to formation of $\mathrm{C}=\mathrm{N}$ bond showed that our required product might be formed by condensation of benzil with p-cresolamine and furfural. Peak at 1575 $\mathrm{cm}^{-1}$ might be due to $(\mathrm{C}=\mathrm{C})$ of aromatic imidazole ring. Peak due to $\mathrm{sp}^{2}(\mathrm{C}-\mathrm{H})$ also appeared at $\left(3058 \mathrm{~cm}^{-}\right.$ $\left.{ }^{1}\right)$. The band due to $\mathrm{OH}$ stretching frequency appeared at $3315 \mathrm{~cm}^{-1}$. Peak due to $\mathrm{C}-\mathrm{O}$ stretching frequency also observed at $1325 \mathrm{~cm}^{-1}$. However, the remaining peaks of different groups did not change any more.

\section{IR spectra of 5-methyl-2-(2,4,5-triphenyl-1H-imidazole- 1-yl)phenol (K3)}

Some selected IR values of K3 are given in Table 4. Peak at $1656 \mathrm{~cm}^{-1}$ indicates the formation of $\mathrm{C}=\mathrm{N}$ linkage present in imidazole ring. This shows that imino bond which is required to establish might be formed by condensation of benzil with pcresolamine and benzaldehyde. Peak at $1522 \mathrm{~cm}^{-1}$ shows the presence of $\mathrm{C}=\mathrm{C}$ which may be of aromatic imidazole ring. Peak of $\mathrm{sp}^{2}(\mathrm{C}-\mathrm{H})$ appeared at $3065 \mathrm{~cm}$ ${ }^{1}$. Another new peak also appeared at $1449 \mathrm{~cm}^{-1}$ which may be due to $\mathrm{C}-\mathrm{N}$ stretching frequency. This also indicates the formation of required product. Peaks at $3305 \mathrm{~cm}^{-1}$ due to $\mathrm{OH}$ stretching frequency and at 2908 $\mathrm{cm}^{-1}$ due to $\mathrm{sp}^{3}(\mathrm{C}-\mathrm{H})$ are the indications of desired product development. Peak at $1680 \mathrm{~cm}^{-1}$ due to benzil carbonyl was missing that shows the complete condensation reaction of benzil with other reagents. All other peaks were not changed significantly.

Table 4: Some selected IR peaks of synthesized compounds (K1, K2 and K3):

\begin{tabular}{cccc}
\hline & \multicolumn{3}{c}{ Compound } \\
Parameter & K1 & K2 & K3 \\
\hline $\mathrm{C}=\mathrm{N}\left(\mathrm{cm}^{-1}\right)$ & 1650 & 1658 & 1656 \\
$\mathrm{C}-\mathrm{N}\left(\mathrm{cm}^{-1}\right)$ & 1440 & 1449 & 1419 \\
$\mathrm{OH}\left(\mathrm{cm}^{-1}\right)$ & 3345 & 3315 & 3305 \\
$\mathrm{C}-\mathrm{O}\left(\mathrm{cm}^{-1}\right)$ & $\mathrm{NA}$ & 3125 & $\mathrm{NA}$ \\
\hline
\end{tabular}

Biological study

\section{Antibacterial Activity (in-vitro)}

The biological activity of all three synthesized compounds (K1, K2, K3) was checked against one Gram negative (Escherichia coli) and two Gram positive
(Bacillus subtilis, Staphylococcus aureus) following published literature [31]. The results obtained by compounds were compared with a standard drug (Ciprofloxacin). Synthesized compounds had major action toward bacterial species. Compound K2 has been found to have the greatest efficacy against certain strains of bacteria. On the other hand, lowest activity was shown by compound $\mathrm{K} 1$. The compounds $\mathrm{K} 2$ and $\mathrm{K} 3$ presented promising results $(>20 \mathrm{~mm})$ against all bacterial strains. The compound $\mathrm{K} 2$ demonstrated maximum activity among all three compounds $(23 \mathrm{~mm})$ against Bacillus subtilis (Table 5).

Table 5: Details of anti-bacterial study of the synthesized compounds (K1, K2 and $\mathrm{K} 3$ ):

\begin{tabular}{ccccc|}
\hline $\begin{array}{c}\text { Bacterial } \\
\text { strains }\end{array}$ & K1 & K2 & K3 & Ciprofloxacin \\
\hline \multicolumn{5}{c|}{ Gram-positive } \\
\hline $\begin{array}{c}\text { Staphylococcus } \\
\text { aureus }(\text { mm })\end{array}$ & 19 & 21 & 20 & 27 \\
$\begin{array}{c}\text { Bacillus subtilis } \\
(\mathrm{mm})\end{array}$ & 18 & 23 & 20 & 29 \\
\hline \multicolumn{5}{c}{ Gram-negative } \\
\hline $\begin{array}{c}\text { Escherichia coli } \\
(\mathrm{mm})\end{array}$ & 16 & 22 & 21 & 27 \\
\hline
\end{tabular}

\section{CONCLUSION}

In present work, we synthesized three novel tetrasubsituted imidazole compounds using multicomponent one pot synthesis scheme. To elucidate the structures of synthesized compounds, characterization was performed by spectroscopic techniques (FT-IR and UV-Visible). Chemically modified compounds have been checked against different bacterial strains to verify biological activity (Staphylococcus aureus, Bacillus subtilis, Escherichia coli). The present study demonstrated that the novel synthesized compounds possess reasonable activity against bacterial strains, worth considering for further studies.

\section{MATERIALS \& METHODS}

All chemicals used in this work were of laboratory quality (analytical) obtained from Sigma Aldrich by chemical suppliers. The purchased chemicals were used in the synthesis without any further refinement and action. The solvents used in the research were also purchased from chemicals suppliers and before use they were distilled. The reactions were monitored using thin layer chromatography proceedings and chromatographic plates were irradiated in U.V and then assessed in iodine vapors. In order to check the percentage composition of newly synthesized compounds, elemental analysis by EL III CHNOS elemental analyzer (Elementar, Hanau, Germany) was accomplished. 


\section{Instrumentation}

For the purpose of both heating and stirring the reaction materials, magnetic stirrer hot plate with stirring range 50 to $1200 \mathrm{rpm}$ and heating range $\left(60-200{ }^{\circ} \mathrm{C}\right)$ was applied. To weigh the materials, AX200, Shimadzu, Japan modal was used. The melting point of newly synthesized compounds was determined by using melting point apparatus (Gallen Kamp). Agilent technology (Cary-620) FTRIR spectrophotometer was used to check the presence of desired functional groups of synthesized compounds by taking IR Spectra. SHIMADZU UV 240 spectrophotometer was used to obtain the spectrum of $\mathrm{U} . \mathrm{V} / \mathrm{V}$ isible technique. To measure the conductivity of synthesized compounds, SDT-600 conductivity meter was used. Elemental analysis was performed by using EL III CHNOS elemental analyzer (Elementar, Hanau, Germany) to check the percentage composition of elements in synthesized compounds.

\section{General method for the synthesis of compounds; K1, K2 and $\mathrm{K} 3$}

Tetrasubsituted imidazole derivatives (K1, K2 and K3) were synthesized according to reported protocol with small variations.

\section{Synthesis of 5-methyl-2-(2-methyl-4,5-diphenyl-1H- imidazol-1-yl)phenol (K1)}

Benzil (1.05 g, $0.005 \mathrm{mmol})$ and acetaldehyde $(0.22 \mathrm{~g}, 0.005 \mathrm{mmol})$ were dissolved in glacial acetic acid at room temperature. After that, p-cresolamine $(0.62 \mathrm{~g}$, $0.005 \mathrm{mmol})$ and ammonium acetate $(0.38 \mathrm{~g}, 0.005 \mathrm{mmol})$ were added to reaction mixture. The reaction was with a reflux the mixture at $110{ }^{\circ} \mathrm{C}$ for 12 hours. TLC was used to monitor the reaction progress. After 12 hours, the volume of the mixture was reduced to half by heating. For slow evaporation, the mixture was kept in a beaker. Crystals of K1 were obtained within a week (Figure 5). Crystals purification was performed by first washing with ethyl acetate and then with ethyl alcohol. The yield of desired compound was about $75 \%$ and that of melting point was $182-184^{\circ} \mathrm{C}$. Elemental analysis: Calculated for $\mathrm{C}_{23} \mathrm{H}_{20} \mathrm{~N}_{2} \mathrm{O}$ (340.41): C, 81.15; H, 5.92; N, 8.23; O, 4.70 \%; Obtained: C, 81.05; H, 5.89; N, 8.13; O, $4.65 \%$.
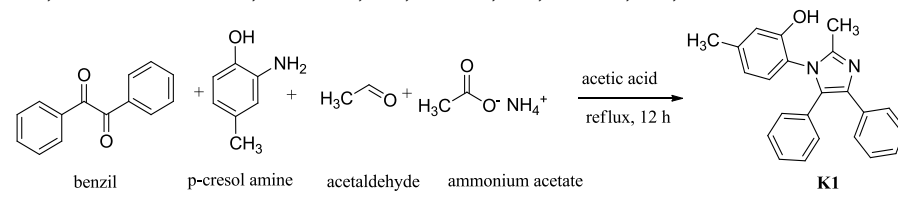

Figure 5: Synthesis of 5-methyl-2-(2-methyl-4,5-diphenyl-1Himidazol-1-yl)phenol (K1).

\section{Synthesis of 2-[2-(furan-2-yl)-4,5-diphenyl-1H- imidazol-1-yl]-5- methylphenol (K2)}

Benzil (1.05 g, $0.005 \mathrm{mmol})$ and furfural $(0.36 \mathrm{ml}$, $0.005 \mathrm{mmol}$ ) were dissolved in glacial acetic acid at room temperature. After that, p-cresolamine $(0.62 \mathrm{~g}, 0.005$ mmol) and ammonium acetate $(0.38 \mathrm{~g}, 0.005 \mathrm{mmol})$ were added to reaction mixture. The reaction was by the refluxing of the mixture at $110^{\circ} \mathrm{C}$ for 12 hours. TLC was used to monitor the reaction progress. After 12 hours, the volume of the mixture was reduced to half by heating. For slow evaporation, the mixture was kept in a beaker. Crystals of K2 were obtained within a week (Figure 6). Crystals purification was performed by first washing with ethyl acetate and then with ethyl alcohol. The yield of desired compound was about $81 \%$ and that of melting point was $195-197{ }^{\circ} \mathrm{C}$. Elemental Analysis: Calculated for $\mathrm{C}_{26} \mathrm{H}_{20} \mathrm{~N}_{2} \mathrm{O}_{2}$ (392.44): C, 79.57; H, 5.14; N, 7.14; O, 8.15 $\%$; Obtained: C, 79.51; H, 5.11; N, 7.08; O, $8.03 \%$.

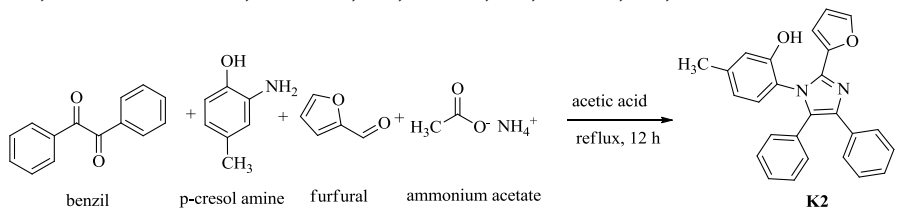

Figure 6: Synthesis of 2-[2-(furan-2-yl)-4,5-diphenyl-1Himidazol-1-yl]-5- methylphenol (K2).

\section{Synthesis of 5-methyl-2-(2, 4, 5-triphenyl-1H-imidazole- 1-yl) phenol (K3)}

Benzil (1.05 g, $0.005 \mathrm{mmol})$ and benzaldehyde $(0.53 \mathrm{~g}, 0.005 \mathrm{mmol})$ were dissolved in glacial acetic acid at room temperature. After that, p-cresolamine $(0.62 \mathrm{~g}$, $0.005 \mathrm{mmol})$ and ammonium acetate $(0.38 \mathrm{~g}, 0.005 \mathrm{mmol})$ were added to reaction mixture. The reaction was done by refluxing the mixture. at $110{ }^{\circ} \mathrm{C}$ for 12 hours. TLC was used to monitor the reaction progress. After 12 hours, the volume of the mixture was reduced to half by heating. For slow evaporation, the mixture was kept in a beaker. Crystals of K3 were obtained within a week (Figure 7). Crystals purification was performed by first washing with ethyl acetate and then with ethyl alcohol. The yield of desired compound was about $70 \%$ and that of melting point was $206-208{ }^{\circ} \mathrm{C}$. Elemental analysis: Calculated for $\mathrm{C}_{28} \mathrm{H}_{22} \mathrm{~N}_{2} \mathrm{O}$ (402.48): C, 83.56; H, 5.51; N, 6.96; O, 3.98 $\%$; Obtained: C, 83.22; H, 5.41; N, 6.84; O, $3.92 \%$.

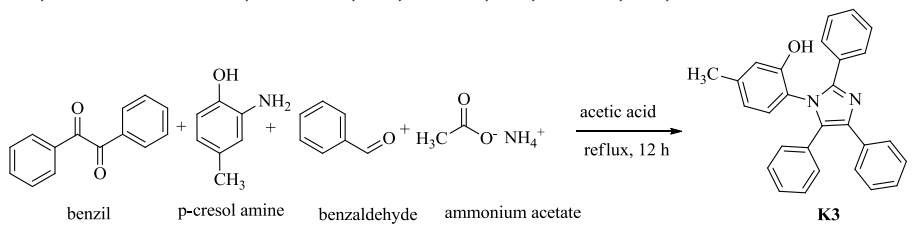

Figure 7: Synthesis of 5-methyl-2-(2, 4, 5-triphenyl-1Himidazole-1-yl) phenol (K3).

Author's contribution: KS designed the study. FA \& SA involved in executing the study and collecting the data. FA \& DP involved in analyzing and validating the data. MK \& MUT were involved in writing and editing the manuscript. All authors have read and approved the final manuscript. 
Acknowledgement: Authors would like to thank Mr. Abrar Ahmad, CEO, SRC (Pvt) Ltd. Lahore, Pakistan for providing access to necessary facilities for obtaining IR spectra at their $\mathrm{R}$ \& D Labs. Authors are also thankful to Dr. Muhammad Shahid, Associate Professor, Department of Biochemistry, University of Agriculture, Faisalabad, Pakistan, for providing access necessary facilities to study the antimicrobial activities in his lab.

\section{REFERENCES}

1. Hill, R.A., Marine natural products. Annual Reports Section "B" (Organic Chemistry), 105 (2009): 150-166.

2. Forte, B., et al., A submarine journey: The pyrrole-imidazole alkaloids. Marine drugs, 7.4 (2009): 705-753.

3. Jin, Z., Muscarine, imidazole, oxazole, and thiazole alkaloids. Natural Product Reports, 28.6 (2011): 1143-1191.

4. Kumar, V.S., et al., Synthesis, spectral properties, chemical descriptors and light harvesting studies of a new bioactive azo imidazole compound. Journal of Molecular Structure,1199 (2020): 127035.

5. Lungu, C.N., et al., Hybrid imidazole-pyridine derivatives: An approach to novel anticancer DNA intercalators. Current medicinal chemistry,27.1 (2020): 154-169.

6. Bhatnagar, A., P. Sharma, and N. Kumar, A review on "Imidazoles": Their chemistry and pharmacological potentials. Int J PharmTech Res, 3.1 (2011): 268-282.

7. Boiani, M. and M. González, Imidazole and benzimidazole derivatives as chemotherapeutic agents. Mini reviews in medicinal chemistry, 5.4 (2005): 409-424.

8. Anderson, E.B. and T.E. Long, Imidazole- and imidazoliumcontaining polymers for biology and material science applications. Polymer, 51.12 (2010): 2447-2454.

9. Green, M.T., Imidazole-ligated compound I intermediates: The effects of hydrogen bonding. Journal of the American Chemical Society, 122.39 (2000): 9495-9499.

10. Zhang, L., et al., Comprehensive review in current developments of imidazole-based medicinal chemistry. Medicinal research reviews, 34.2 (2014): 340-437.

11. Zheng, X., Z. Ma, and D. Zhang, Synthesis of Imidazole-Based Medicinal Molecules Utilizing the van Leusen Imidazole Synthesis. Pharmaceuticals, 13.3 (2020): 37.

12. Jin, Z., Imidazole, oxazole and thiazole alkaloids. Natural product reports, 23.3 (2006): 464-496.

13. Jin, Z., Z. Li, and $\mathrm{R}$. Huang, Muscarine, imidazole, oxazole, thiazole, Amaryllidaceae and Sceletium alkaloids. Natural Product Reports, 19.4 (2002): 454-476.

14. Pattabiraman, V.R. and J.W. Bode, Rethinking amide bond synthesis. Nature, 480.7378 (2011): 471.

15. $\mathrm{H}$ Zhou, $\mathrm{C}$. and $\mathrm{Y}$. Wang, Recent researches in triazole compounds as medicinal drugs. Current medicinal chemistry, 19.2 (2012): 239-280.

16. Angyal, A., et al., Acid-Catalyzed 1,3-Dipolar Cycloaddition of 2H-Azirines with Nitrones: An Unexpected Access to 1,2,4,5Tetrasubstituted Imidazoles. The Journal of Organic Chemistry, 85.5 (2020): 3587-3595.

17. Alkahtani, H.M., A.Y. Abbas, and S. Wang, Synthesis and biological evaluation of benzo[d]imidazole derivatives as potential anti-cancer agents. Bioorganic \& Medicinal Chemistry Letters, 22.3 (2012): 1317-1321.

18. Hu, Y., et al., Synthesis and biological evaluation of coumarin derivatives containing imidazole skeleton as potential antibacterial agents. European journal of medicinal chemistry, 143 (2018): 958969.

19. Verma, A., S. Joshi, and D. Singh, Imidazole: Having versatile biological activities. Journal of Chemistry, (2013): 1-12.
20. Shad, H., et al., Multi-Component Synthesis of Novel Diazoles: their Characterization and Biological Evaluation. Arc Org Inorg Chem Sci 1.2 (2018): 107.

21. Steinman, R.A., A.M. Brufsky, and S. Oesterreich, Zoledronic acid effectiveness against breast cancer metastases-a role for estrogen in the microenvironment? Breast Cancer Research, 14.5 (2012): 213.

22. Mishra, R. and S. Ganguly, Imidazole as an anti-epileptic: an overview. Medicinal Chemistry Research, 21.12 (2012): 39293939.

23. Burnier, M. and G. Wuerzner, Pharmacokinetic evaluation of losartan. Expert opinion on drug metabolism \& toxicology, 7.5 (2011): 643-649.

24. Abdel-Wahab, B.F., G.E.A. Awad, and F.A. Badria, Synthesis, antimicrobial, antioxidant, anti-hemolytic and cytotoxic evaluation of new imidazole-based heterocycles. European Journal of Medicinal Chemistry, 46.5 (2011): 1505-1511.

25. Sharma, D., et al., Synthesis, antimicrobial and antiviral evaluation of substituted imidazole derivatives. European Journal of Medicinal Chemistry, 44.6 (2009): 2347-2353.

26. Kantevari, S., et al., Highly efficient, one-pot, solvent-free synthesis of tetrasubstituted imidazoles using $\mathrm{HClO} 4-\mathrm{SiO} 2$ as novel heterogeneous catalyst. Journal of Molecular Catalysis A: Chemical, 266.1-2 (2007): 109-113.

27. Toure, B.B. and D.G. Hall, Natural product synthesis using multicomponent reaction strategies. Chemical Reviews, 109.9 (2009): 4439-4486.

28. Lombardino, J.G. and E.H. Wiseman, Preparation and antiinflammatory activity of some nonacidic trisubstituted imidazoles. Journal of Medicinal Chemistry, 17.11 (1974):. 11821188.

29. Sondhi, S.M., et al., Synthesis of some thiophene, imidazole and pyridine derivatives exhibiting good anti-inflammatory and analgesic activities. Medicinal Chemistry, 4.2 (2008): 146-154.

30. Wittine, K., et al., Novel 1, 2, 4-triazole and imidazole derivatives of L-ascorbic and imino-ascorbic acid: Synthesis, anti-HCV and antitumor activity evaluations. Bioorganic \& medicinal chemistry, 20.11 (2012): 3675-3685.

31. Choudhary, M.I. and W.J. Thomsen, Bioassay techniques for drug development. CRC Press, (2001): 1-240.

Submit your next manuscript to Journal of PeerScientist and take full advantage of:

- High visibility of your research across globe via PeerScientist network.

- Easy to submit online article submission system.

- Thorough peer review by experts in the field.

- Highly flexible publication fee policy.

- Immediate publication upon acceptance.

- Open access publication for unrestricted distribution.

Submit your manuscript online at:

http://journal.peerscientist.com/

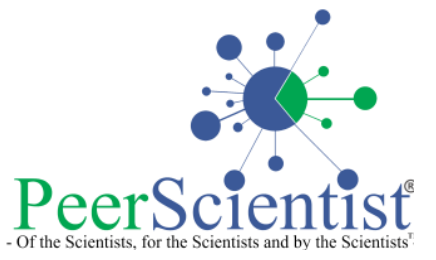

